Revista Española de Antropología Americana ISSN: 0556-6533

https://doi.org/10.5209/reaa.66529

\title{
Dos escenarios para la recreación del mito: el Patio Este y la Casa E del Palacio en Palenque
}

\author{
Felix Kupprat ${ }^{1}$
}

Recibido: 5 de marzo de 2019/ Aceptado: 5 de septiembre de 2019

Resumen. La recreación de lugares mitológicos en el espacio construido fue una práctica común entre los mayas del periodo Clásico. Especialmente los templos y las plazas han sido asociados con conceptos cosmológicos y ubicaciones sobrenaturales específicas. No obstante, la identificación e interpretación de estos paisajes primordiales plasmados en los contextos urbanos es difícil y, en muchos casos, hipotética. De manera general, se requiere de varias líneas de evidencia para detectar este tipo de representaciones simbólicas, como por ejemplo imágenes, textos, elementos arquitectónicos y configuraciones espaciales. En este artículo se mostrará cómo la escultura y la arquitectura creaban escenarios mitológicos para ciertos espectáculos que se llevaron a cabo en y alrededor de los edificios del Palacio en Palenque. El Patio Este y la Casa E eran espacios para la recreación de mitos que giran en torno a Balun Yookte' K'uh y el dios del maíz, respectivamente.

Palabras clave: escenarios mitológicos mayas; Palenque; escultura integrada en la arquitectura; Balun Yookte' K'uh; dios del maíz

\section{[en] Two Mythological Sceneries in Palenque: The East Court and House E}

\begin{abstract}
The recreation of mythological places in the built environment was a common practice among the Maya of the Classic period. Especially temples and plazas have been associated with cosmological concepts and specific supernatural locations. Nevertheless, the identification and interpretation of these urban reflexes of primordial landscapes is a difficult task that usually results in refined hypotheses. In general, a successful analysis of this kind of symbolic representations requires multiple lines of evidence, such as images, texts, architectural features, and the configuration of space. In this article, I point out how sculpture and architecture created mythological sceneries for certain performances that where conducted in and around the buildings of the Palace in Palenque. The East Court and House E were spaces perceived for the recreation of mythological narratives that deal with Balun Yookte' K'uh and the Maize God, respectively.
\end{abstract}

Keywords: mythological sceneries of the Maya; Palenque; architecturally integrated sculpture; Balun Yookte' K'uh; Maize God

Sumario. 1. Introducción. 2. El Patio Este. 3. La Casa E. 4. Conclusiones. 5. Referencias.

Cómo citar: Kupprat, Felix. 2019. «Dos escenarios para la recreación del mito: el Patio Este y la Casa E del Palacio en Palenque». Revista Española de Antropología Americana 49: 217-238.

\footnotetext{
1 Universidad Nacional Autónoma de México, Programa de Becas Posdoctorales. Becario del Instituto de Investigaciones Antropológicas. kupprat@gmail.com
} 


\section{Introducción}

A lo largo de los siglos, los mayas del periodo Clásico recrearon una cantidad considerable de lugares primordiales y mitológicos en el espacio físico. Al menos desde los estudios de Linda Schele y sus colegas (Freidel et al. 1993: 123-172; Schele 1998; Schele y Mathews 1998: 13-48; véase también; Reese 1996; Taube 1998; Carrasco y Hull 2002), las construcciones monumentales en los centros de las ciudades, así como los espacios abiertos entre ellas, se han considerado modelos del cosmos maya, con montañas sagradas y plazas marinas, convirtiendo el paisaje urbano en un escenario para un «eterno retorno» (Eliade 2001) al origen del mundo y al ámbito de los dioses y de los antepasados. Este principio adquiere especial relevancia cuando se consideran las actividades rituales que se llevaron a cabo en estos espacios (Schele y Mathews 1998: 23; véase también Reese 1996: 139-177; Carrasco 2005; Valencia 2015: 287-292; Werness-Rude y Spencer 2015; para ejemplos mesoamericanos véase Koontz et al. 2001; Pope 2006; López Austin y López Luján 2009).

En este estudio se discutirán algunos casos presentes en el Palenque del siglo VII que ilustran la identificación de topoi míticos que fueron recreados como parte del discurso monumental del gobernante K'ihnich Janaab Pakal (615-683 d.C.). Por su abundancia en escultura y texto, Palenque ha sido el objeto de una inmensa cantidad de estudios, incluyendo varios análisis arquitectónico-iconográficos de edificios en el centro de la ciudad. Mientras que los grandes templos -sobre todo el Grupo de las Cruces (Schele y Freidel 1990: 237-261; Robertson 1991; Freidel et al. 1993: 144-146; Child 2007; Stuart y Stuart 2008: 191-215; Parmington 2011: 48-67) y el Templo de las Inscripciones (Ruz Lhuillier 2013: 216-217; Schele y Mathews 1998: 95-132)- han recibido mucha atención con respecto a esta problemática, las representaciones mitológicas en otros conjuntos arquitectónicos, como el Palacio, han entrado en esta discusión en años más recientes (ver Stuart y Stuart 2008: 161; Parmington 2011: 68-133; Carrasco 2015: 394-402). En este artículo presentaré algunas nuevas interpretaciones sobre los significados y las funciones de dos espacios del Palacio, con el fin de ilustrar las posibilidades del análisis icono-semiótico y discutir las bases metodológicas para el estudio de los espacios mítico-arquitectónicos.

\section{El Patio Este}

Uno de los espacios más emblemáticos del Palacio de Palenque (Figura 1) es el Patio Este, no sólo por su tamaño, siendo el patio de mayor extensión, sino sobre todo por los mensajes violentos de las esculturas de cautivos que lo rodean. K'ihnich Janaab Pakal, el gobernante palencano que gobernó durante la mayor parte del siglo VII d.C. (véase Mathews y Schele 1974; Stuart y Stuart 2008: 246; de la Garza et al. 2012: 283-290), aparentemente utilizó este espacio para demostrar su éxito militar y para intimidar a cualquiera que tan solo pensara en oponerse a él.

No obstante, la apariencia actual del Patio Este, un aproximado cuadrángulo cerrado por las impresionantes Casas C, B, A y A-D alrededor, engaña al visitante moderno, pues su forma fue definida paulatinamente a lo largo de más de medio siglo. Después de la última nivelación del basamento del Palacio en la época de Janaab Pakal, el Patio Este era probablemente mucho más abierto y los primeros 


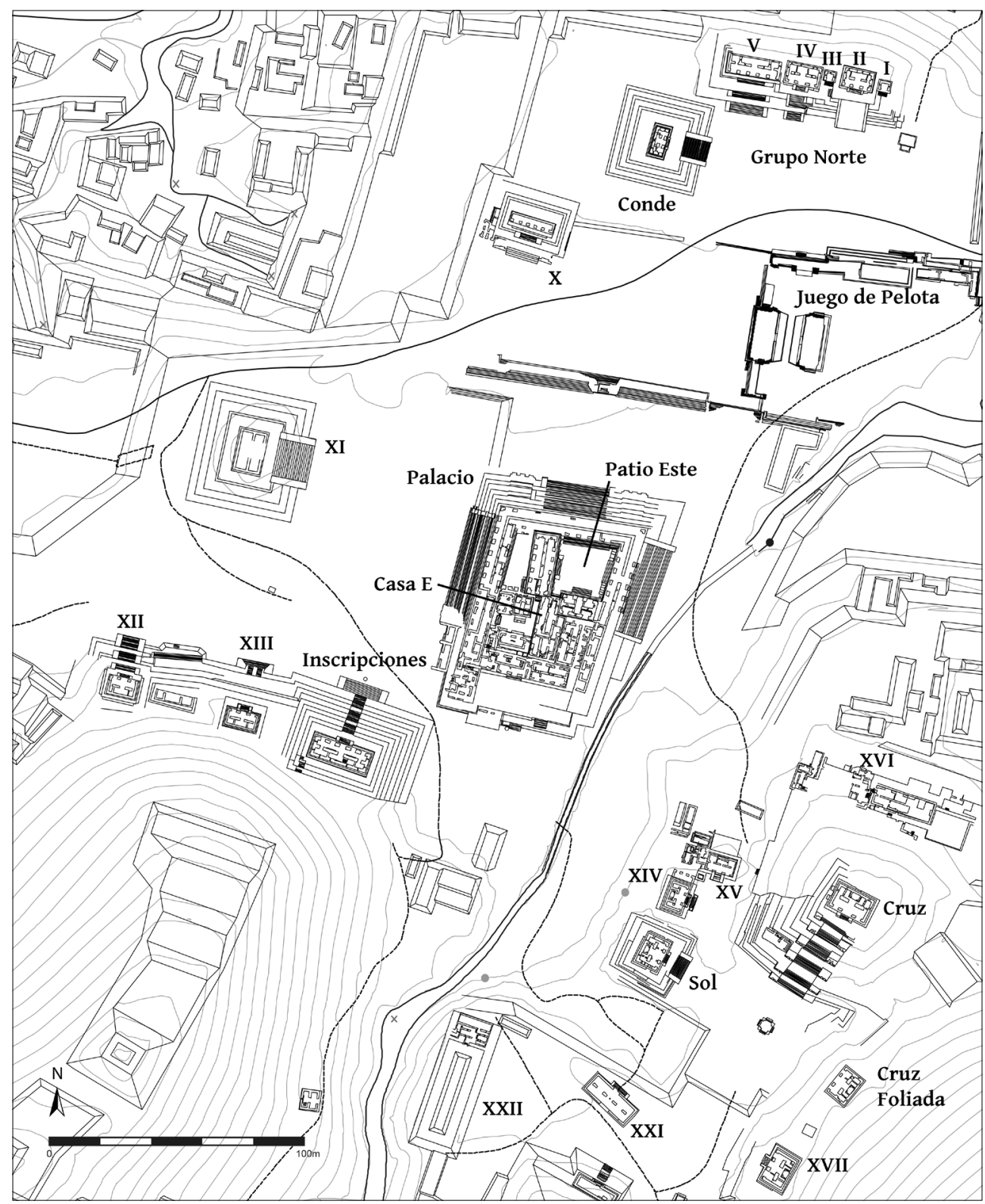

Figura 1. Mapa del Palacio y sus alrededores (mapa cortesía de Edwin Barnhart, 2001: 8, mapa 2.1, con modificaciones menores).

edificios que lo delimitaban eran las Casas B y C, la última dedicada en 661 d.C. Sólo seis años después, se inauguró la Casa A, en el extremo este del patio (Schele 1986; Stuart 1998: 392, tabla 1; 2014; Martin y Grube 2008: 163; Stuart y Stuart 2008: 156-161; de la Garza et al. 2012: 99-100). En esta época, la entrada principal al Palacio se encontraba al norte y el Patio Este conectaba inmediatamente con ella, 
convirtiéndolo en el espacio más accesible $\mathrm{y}$, por ende, más público del conjunto (Figura 2) ${ }^{2}$.

Integrados en el basamento de la Casa C, así como en las alfardas de su escalera, se encuentran los retratos homogeneizados de varios cautivos arrodillados, marcados como tales a través de tiras de papel en sus orejas (Robertson 1985b: fig. 322-328; Schele y Schele 2000: no. 142) (Figura 3a). El texto de la Escalinata Jeroglífica relata que los cautivos de la Casa $C$ fueron capturados durante las guerras de Janaab Pakal en 659 d.C. (Baudez y Mathews 1979; Schele 1994; Grube 1996; Martin y Grube 2000: 164-165, 2008: 164-165; Grube et al. 2002: 25; Stuart y Stuart 2008: 159; Bernal 2011: 49-56, 365; de la Garza et al. 2012: 99-100), quien en el texto es caracterizado como Balun Yookte' K'uh, tratándose del nombre de una deidad relacionada con la guerra y el otro mundo

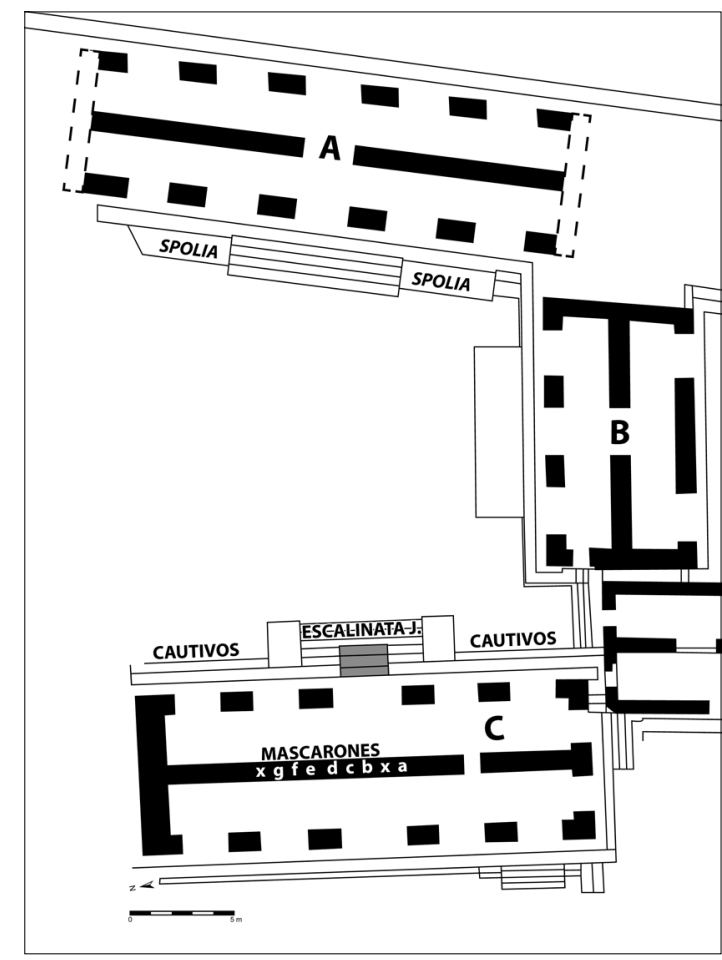

Figura 2. El Patio Este durante el último tercio del siglo VII d.C. (dibujo basado en el plano de Andrews 1978: 9). (Eberl y Prager 2005; Grofe 2009).

Justamente en el otro lado del patio se encuentra una segunda serie de esculturas que posiblemente provienen de otro sitio y que fueron integradas en el basamento de la Casa A como spolia (Baudez y Mathews 1979; D. Robertson 1973: 106; M. Robertson 1985b: 61-66, fig. 286-315; Spencer 2015: 255-257) (Figura 3b). En las inscripciones de dedicación, estas esculturas se caracterizan como ahal 'victoria'4, lo cual en este caso se debe entender como 'botín de guerra's. Lo curioso es que sólo

\footnotetext{
2 Alrededor de 720 d.C., varias décadas después de la muerte de Janaab Pakal, el Patio Este fue cerrado por la Casa A-D (Robertson 1985b: 6, 32; Stuart 1998: 392, tabla 1), lo cual cambió la accesibilidad de este espacio de manera significativa. Antes de esto, el acceso al Palacio era posible a través de las Galerías Norte (ver Parmington 2011: 74, 88, fig. 4.18), las cuales servían para controlar el acceso a los niveles superiores del Palacio. Tanto por esta estructura, como por la altura del basamento del Palacio, la visibilidad del Patio Este desde la plaza al norte y la cancha de juego de pelota ha de haber sido muy reducida desde un principio.

3 Spolia son, de manera general, elementos arquitectónicos o escultóricos que fueron reutilizados en construcciones posteriores. A menudo, la recontextualización de estos elementos se debía a la destrucción bélica y el saqueo de objetos de arte a manera de botines de guerra (Kinney 2011).

4 Una traducción frecuente para ahal (o ahil) es 'amanecer, despertar' o 'creación' (p. ej., Stuart 2005: 174), pero es probable que ahal se derive de una raíz distinta a aj 'amanecer, despertar', ya que ambas aparecen en Palenque en la misma época (véase los ejemplos en Boot 2009: 11-12). La distinción entre $/ \mathrm{h} / \mathrm{y} / \mathrm{j} / \mathrm{se}$ ha conservado en tseltal, donde encontramos entradas como ahalabtay 'tentar, por engañar y vencer, o hacer traición', ahalay 'hacer traición', ahalabil 'engañado' (Ara 1986: 241), las cuales se relacionan semánticamente con las entradas ahali 'vencer' y ahalia 'vencedor' en choltí (Morán 1836: 173), por lo cual la traducción de ahal como 'victoria' es la mejor opción (véase también Kettunen y Helmke 2010: 97).

5 Las dos inscripciones dedicatorias se leen wak ehb? lajuun ihk'at na[']waj yahal kal[o]'m[te'] 'En 6 Eb 10 Uo, la
} 

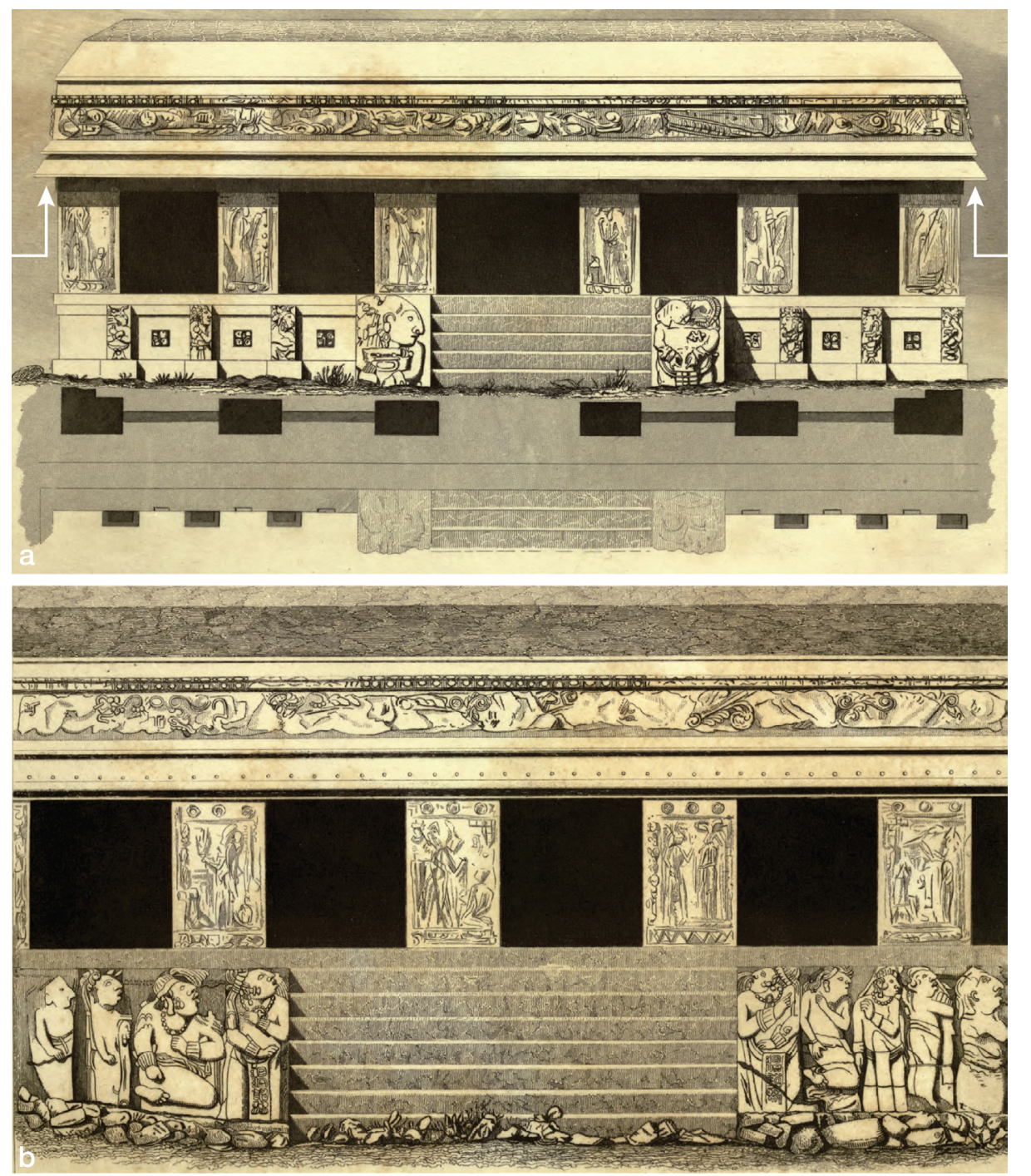

Figura 3. a) Casa C; b) Casa A (dibujos de Frederick Catherwood en Stephens 1841: 315. Las flechas blancas fueron añadidas para marcar la ubicación de la inscripción dedicatoria).

uno de los personajes, el del extremo derecho, está claramente marcado como cautivo. Los demás llevan joyas y tocados, y por lo menos dos están de pie, una postura que jamás se ve en las representaciones de cautivos. Por lo tanto, la escena original

«victoria» del kalo'mte' fue presentada' y tahuk bin? 11 ihk'at na [']waj yahal k'uh [ul] baak[e]'l ajaw 'En 7 Ben 11 Uo, la «victoria» del señor divino de Baake'l fue presentada'. La «victoria» $(a h<a>l$, ahaal o ahali[l]) es, por ende, algo que fue presentado y que el gobernante palencano poseía, probablemente una referencia a las esculturas mismas o a los personajes cautivos representados. Las dedicaciones sucedieron en dos días consecutivos en 662 d.C. (29 de marzo, 9.11.9.10.12, y 30 de marzo, 9.11.9.10.13, respectivamente), es decir menos de tres años después de las capturas conmemoradas en la Escalinata Jeroglífica. Por consiguiente, no queda claro si las esculturas de cautivos de la Casa A se relacionan con la misma campaña militar que las de la Casa C o con otra que se llevó a cabo poco tiempo después. 
probablemente representaba la presentación de un preso por parte de varios nobles. Sin embargo, si consideramos que las esculturas fueron adquiridas en la guerra y trasladadas a Palenque, al igual que los presos vivos, los retratos de los nobles como objetos se convirtieron en cautivos de Janaab Pakal, y en el Patio Este fueron puestos a la par con otros presos. No podemos determinar si sus contrapartes en carne y hueso también fueron capturadas o no.

Todos los cautivos se encuentran sobre el nivel del patio. En el siguiente nivel, en las caras exteriores de los pilares de las Casas A y C se encontraron escenas modeladas en estuco que han desaparecido por completo (Robertson 1985a: 51). Los dibujos de Frederick Catherwood muestran personajes esquemáticos en los pilares (Figura 3), pero en este caso es difícil determinar si reflejan lo que vio el dibujante, o si más bien se trata de una reconstrucción libre. Los vagos contornos que se oponen a las líneas definidas de los cautivos, así como la aparente invención de los motivos del friso del techo de la Casa C (compárese Figuras 3a y 4a) indican lo último. Empero, su interpretación probablemente no fue equivocada, ya que todos los pilares estucados contemporáneos muestran a personajes reales en distintos entornos y situaciones sociales. En los pilares de la Casa B aún se distinguen algunos fragmentos de personajes de pie (Robertson 1985a: 41-43, fig. 145-153), y debemos asumir que todos los pilares exteriores del Patio Este mostraban a Janaab Pakal u otros nobles de alto rango social, claramente separados de los cautivos en el patio, de pie o sentados sobre ellos, pues se encuentran sobre el nivel de los basamentos.

Encima de los pilares de la Casa $\mathrm{C}$, en la superficie inferior de unas lajas que forman la base de la cornisa del techo, fue inscrito un texto dedicatorio (Maudslay 1889-1902: tomo 4, 17; Robertson 1985b: 69, fig. 335-336) (Figura 4). Este texto (Figura 4b) menciona no sólo a Janaab Pakal, sino a una serie de númenes que son, de alguna manera, dueños de la casa: Balun Yookte' K'uh, un dios cuyo nombre aún no ha sido descifrado, K'awiil y Yax Chit K' $\mathrm{uh}^{6}$. Como se mencionó anteriormente, Balun Yookte' K'uh también forma parte del nombre de Janaab Pakal en el texto de la Escalinata Jeroglífica, donde el gobernante adquiere la identidad de esta deidad en el marco de sus victorias militares (Prager 2013: 478-483).

Esta correspondencia es significativa cuando la relacionamos con el interior de la Casa C. En la crujía este se encontraban nueve mascarones modelados en estuco, justamente debajo del arranque de la bóveda. Siete de ellos están parcialmente preservados (Figura 5), mientras que los otros dos se han perdido (Robertson 1985a: 51). Todos los mascarones son distintos y representan los rostros de entidades sobrenaturales. De cuatro de los mascarones preservados (a-d) salen hojas vegetales de diferentes formas y tamaños. Otro mascarón (g) también cuenta con un elemento vegetal, pero de carácter acuático. Por consiguiente, el elemento vegetal parece ser la constante en todos los mascarones; en los dos casos en que este rasgo no es aparente, los motivos vegetales parecen haberse deteriorado.

En el arte maya, las cabezas sobrenaturales frecuentemente aparecen como bases de plantas, a manera de raíces y troncos. La comparación de los mascarones con otras imágenes de árboles del Clásico Tardío (Figura 6) muestra que todos represen-

\footnotetext{
${ }^{6}$ Aquí, Yax Chit K'uh parece ser la deidad que también se menciona al principio de la inscripción como dueño o patrón de las lajas de cornisa. No obstante, es probable que chit en Palenque haya sido pronunciado kit, ya que en las orejeras que se hallaron en la tumba de Janaab Pakal se encuentra la expresión u-ki-ti que probablemente sustituye para KIT $\sim$ CHIT.
} 


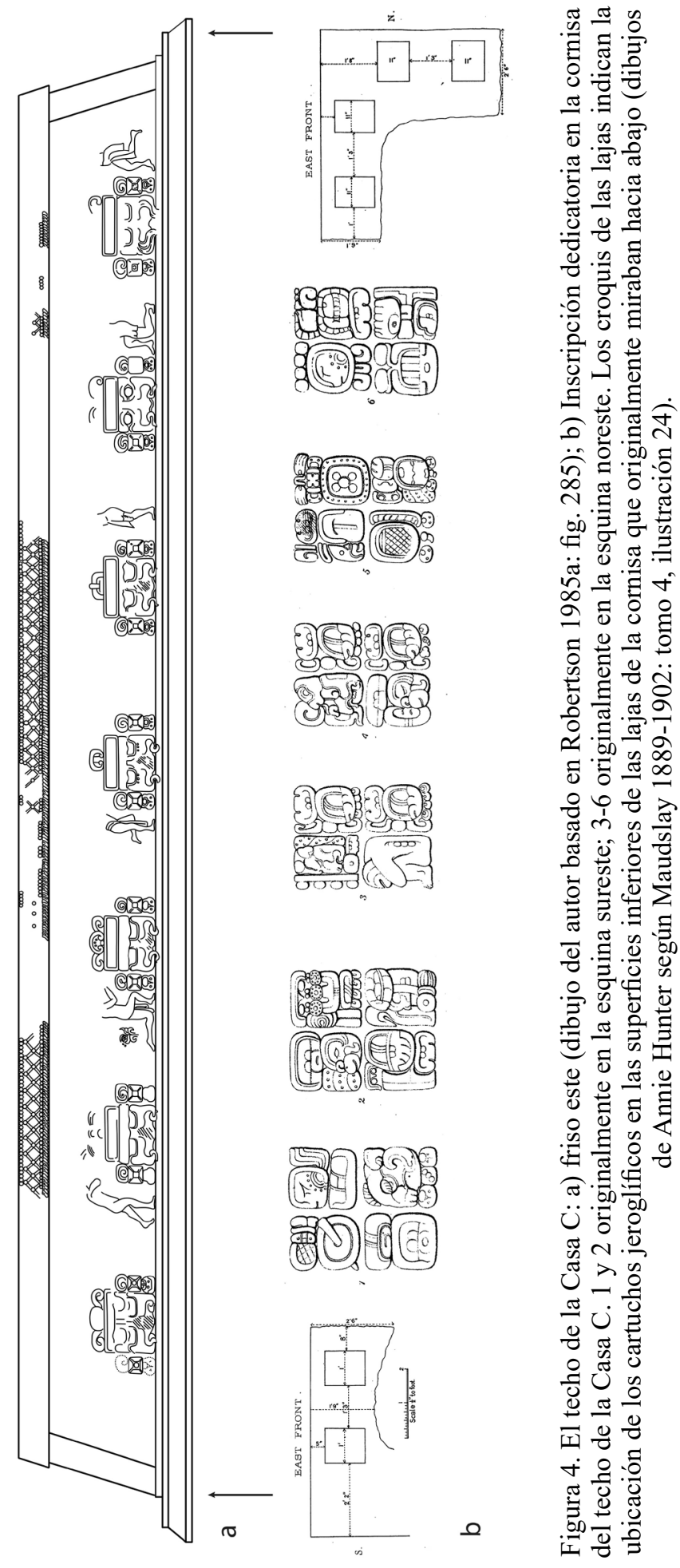




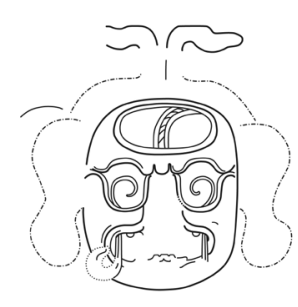

a

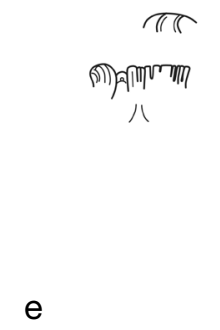

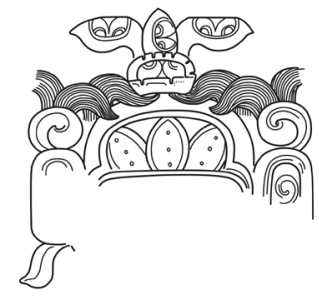

b

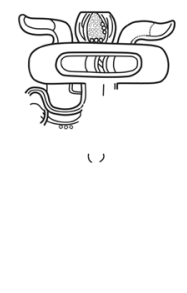

C

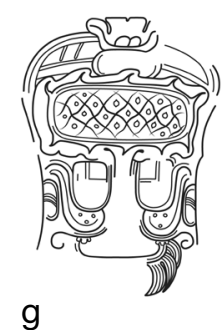

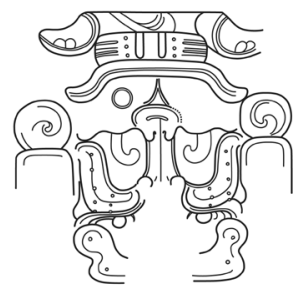

d

Figura 5. Mascarones en la crujía este de la Casa C: a) 1; b) 3; c) 4; d) 5; e) 6; f) 7; g) 8 (dibujos del autor basados en Robertson 1985a: figs. 206, 208, 213, 215, 219, 221).

tan las bases de plantas primordiales. La superficie brillante en la frente y las volutas que emergen de la boca del mascarón a ${ }^{7}$ son rasgos vegetales comunes (compárese con la Figura 6a). En el caso del mascarón c nace una mazorca de dicha frente, lo cual parece ser una compactación visual de la planta de maíz que se aprecia en el tablero principal del Templo de la Cruz Foliada en Palenque (Figura 6b). Aparte del follaje superior, el mascarón d está marcado como raíz de planta por dos rasgos distintivos: por un lado, un signo de semilla ocupa la frente ${ }^{8}$. Un paralelo claro se presenta en las escenas de las vasijas estilo códice, donde el dios del maíz nace de una semilla muy parecida (Figura $6 \mathrm{c}$ ). Por el otro lado, se observa un signo de brasas inmediatamente encima de la semilla. La idea de que las plantas crecen de fogones (brasas o cenizas) (Figura 6d) ${ }^{9}$ y de incensarios (Figuras 6e y f) está ampliamente atestiguada, y también el mascarón f pertenece, por el plato de ofrenda en su frente, a esta categoría de plantas. Finalmente, el mascarón g representa a un nenúfar animado, con el típico diseño de líneas cruzadas (probablemente un caparazón estilizado) en la frente, haciendo referencia a una planta que se presenta en diferentes soportes en toda el área maya a lo largo del periodo Clásico (p. ej. Figura 6g). Las mandíbulas

\footnotetext{
7 De aquí en adelante, la denominación de los mascarones corresponde a la Figura 5.

8 El signo T533 en la frente del mascarón se asocia iconográficamente con huevos, capullos y semillas (Tokovinine 2012: 287-288) y en este caso emergen hojas de él. En la escritura jeroglífica, el signo T533 es polivalente. Aparte del valor AJAW tiene por lo menos un valor alternativo para el cual se han propuesto de manera tentativa lecturas como NIK NICH nik nich 'flor' (Nikolai Grube 1992, comunicación personal con Macri y Looper 2003: 67), BOK book 'odor, hedor' (Prager 2006) o MOK mook 'elote, espiga de maíz, flor de maíz' (Barbara MacLeod y Luis Lopes, comunicación personal con Polyukhovych 2015). Para una discusión del desciframiento (aún inconcluso) de T533 véase el trabajo de Erik Velásquez (2009: 484-494). En años recientes, David Stuart (comunicación personal con Tsukamoto 2014: 287) propuso la lectura SAK saak 'semilla de calabaza, pepita' (agradezco a Erik Velásquez el compartirme este dato). De ser correcta esta propuesta, es posible que aquí se trate de una semilla como raíz de la calabacera.

9 Gracias a Daniel Salazar Lama por haberme indicado este y otros paralelos.
} 


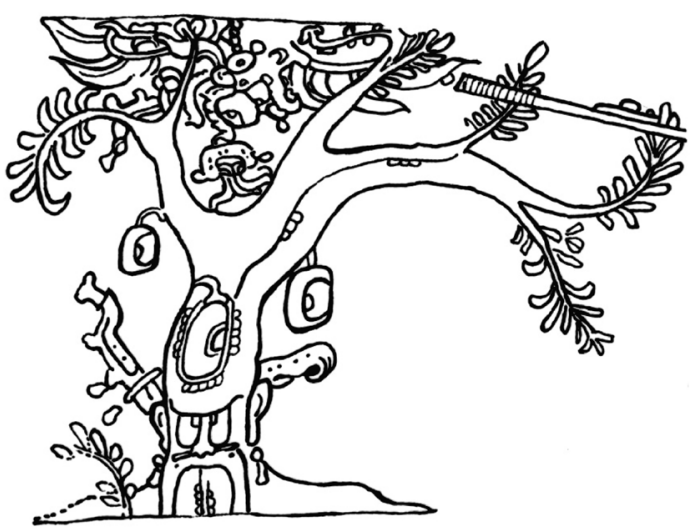

a

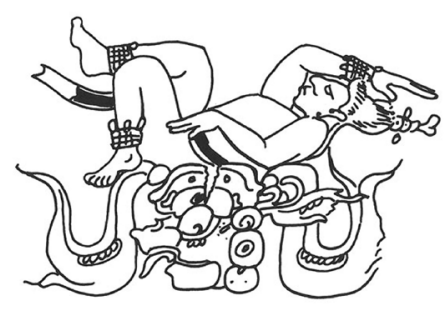

C
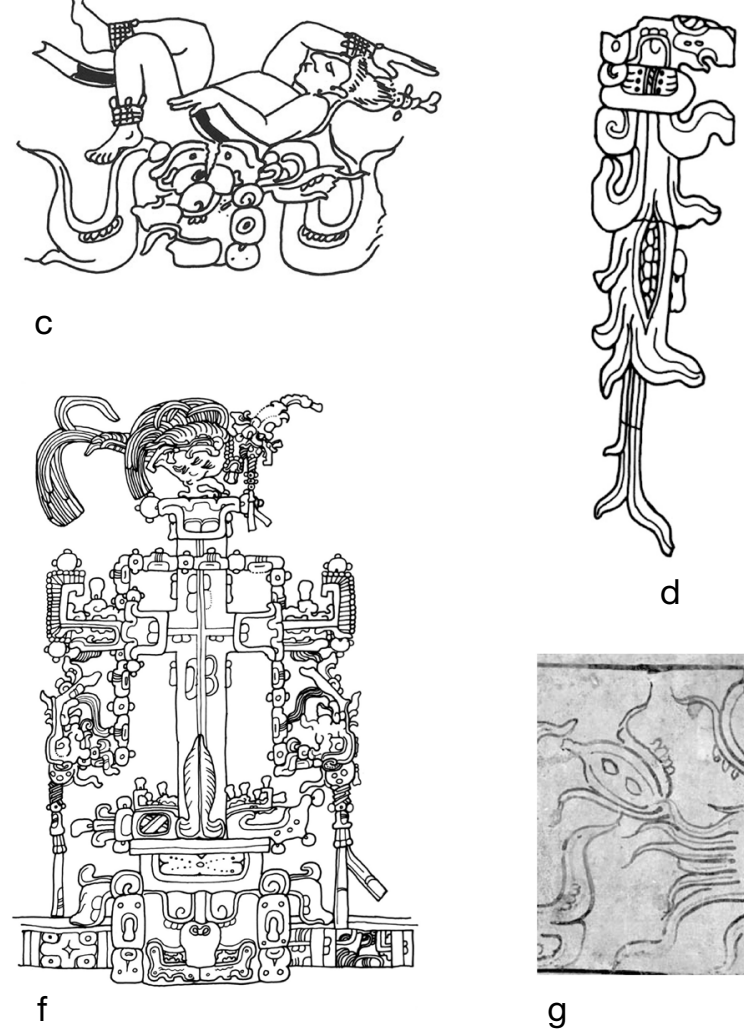

g

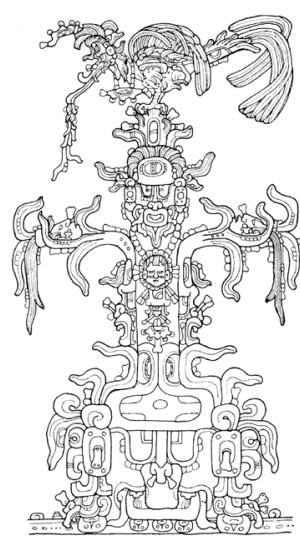

b
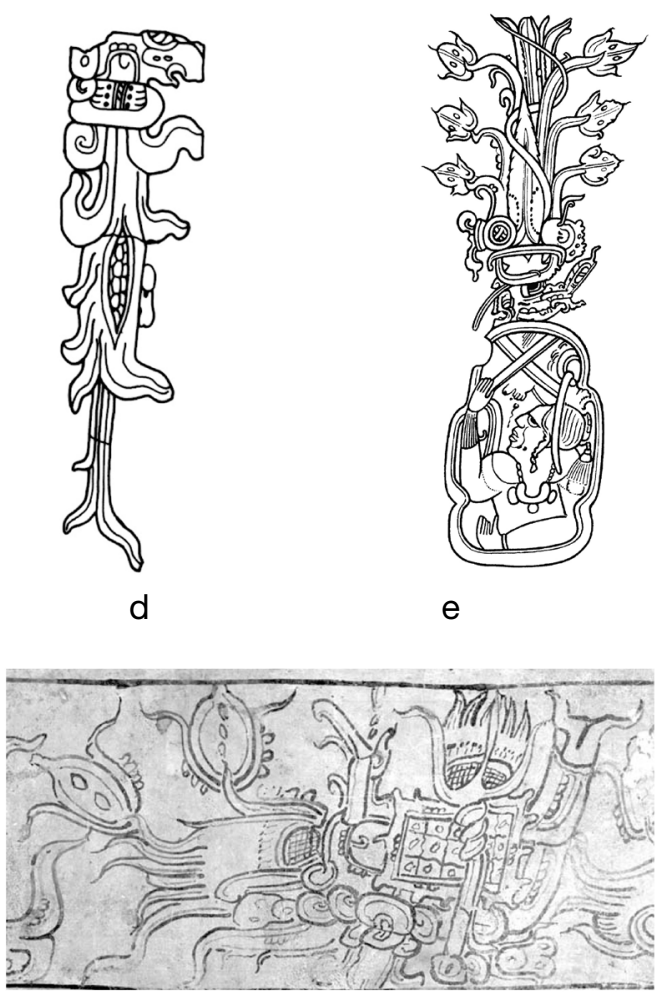

Figura 6. Árboles en el arte maya del Clásico: a) vasija estilo códice, K1126; b) Palenque, tablero principal del Templo de la Cruz Foliada; c) vasija polícroma, K2723; d) Palenque, jamba del santuario norte del Templo del Sol; e) vasija polícroma, K501; f) Palenque, tablero principal del Templo de la Cruz; g) vasija estilo códice, K5628 (dibujos a-d y f de Linda Schele en Schele y Schele 2000: no. 5521, 510, 7668, 177 y 511; dibujo e de Paul Schoenmakers en Wayeb 2008; fotografía g cortesía de Justin Kerr, 2008: no. 5628). 
descarnadas que caracterizan por lo menos dos de los mascarones ( $\mathrm{d}$ y f), representan la parte subterránea de las matas.

Combinando esta evidencia iconográfica con las inscripciones de la cornisa y de la Escalinata Jeroglífica de la Casa C, la identidad de las plantas representadas es evidente: una traducción literal del teónimo Balun Yookte' K'uh, el cual aparece en ambos textos, es 'dios de los nueve troncos de árbol' ${ }^{10}$, así que los mascarones de la Casa $\mathrm{C}$ recrean un paisaje en el cual, por lo menos en el pensamiento de los palencanos del siglo VII, se origina dicho numen. Esto no significa que Balun Yookte' K'uh fuera percibido como grupo de nueve árboles. De hecho, se conocen ciertos atributos de esta deidad que sugieren que Balun Yookte' K'uh fue considerado como un ser singular y actor primordial con fuertes asociaciones bélicas (Eberl y Prager 2005; Prager 2013: 472-500). Los árboles representados en la Casa C probablemente hacen referencia al origen mítico de esta deidad o a un paisaje sobrenatural asociado con ella, pero no al dios mismo. Otra opción es que se trata de una reinterpretación palencana del nombre de este dios.

Los textos de la Casa $\mathrm{C}$ revelan que Janaab Pakal tuvo una relación íntima con Balun Yookte' K'uh. En la escalinata jeroglífica (Schele y Schele 2000: no. 138), los nombres de ambos aparecen como uno sólo, indicando que en este contexto Janaab Pakal es Balun Yookte' K'uh. Esta manera de expresar la personificación de un numen por parte de un ser humano, a través de «teónimos facultativos» (Colas 2004: 263-277), es bastante común y ocurre a menudo con una categoría de deidades que fueron denominadas chit $k^{\prime} u h$ (Prager 2013: 518-525), lo que se puede traducir como 'dios-patrón' o 'dios-compañero'. El texto dedicatorio de la Casa $\mathrm{C}$ sugiere que Balun Yookte' K'uh era un chit k'uh de Janaab Pakal, pues lleva el título 1-na-ta que en otro contexto aparece en conjunto con la expresión yax chit $k^{\prime} u h^{11}$. Es interesante que esta relación sólo se encuentra atestiguada en la Casa C, así que la ubicación aparentemente fue un factor importante para esta alianza entre hombre y dios.

Estos datos ilustran cómo un espacio construido servía como escenario para que el gobernante adquiera una identidad sobrenatural. Posiblemente, esta transformación incluía instrumentos específicos como tocados, máscaras, etc. Al salir de la Casa C, Janaab Pakal aparecía como dios de la guerra y del otro mundo, emergiendo de su morada mítica. La información iconográfica sugiere que esta transformación sucedía en función de la humillación de los cautivos, los cuales se encontraban en el patio mismo, en el plano inferior, expuestos al sol y rodeados por los personajes en piedra que habían compartido su suerte.

La humillación y tortura ritual de cautivos de guerra probablemente no fue la única actividad que se realizaba en el Patio Este, pero es la que mejor entendemos con base en el arreglo arquitectónico y la escultura integrada en él. Si empleamos la idea de que el patio fue un espacio para reunir un público amplio, podríamos esti-

\footnotetext{
${ }^{10}$ yookte' literalmente se traduce como 'pie de árbol' -es decir 'raíces' o 'tronco'-, pero la etimología aún se discute (véase, p. ej., Prager 2013: 475). Esta expresión también aparece en contextos diversos como título (véase Boot 2009: 141), así que es posible que la etimología histórica sea otra. En este caso, los palencanos hubieran reinterpretado un teónimo antiguo cuyo significado original ya no entendían.

11 1-na-ta (los elementos redondos debajo del signo ta probablemente forman parte de este mismo; compárese el signo la en el cuarto bloque jeroglífico) juun na $[h] t$ parece ser un clasificador para los chit $k$ 'uh (dioses patronos [personales] o acompañantes). La vocal aspirada se reconstruye con base en el ejemplo NAH-ta en la Estela 5 de Copán, lo que indica la traducción como ‘uno lejano’ (véase Schele 1994: 7).
} 
mar una capacidad máxima de alrededor de 600 personas $^{12}$, pero un número tan alto implica una visibilidad muy limitada y una movilidad restringida entre el público. Un número de 200 a 300 personas es más probable. No obstante, si asumimos que la mayoría del público se encontraba en las orillas, en las puertas de las casas y en las escaleras, la capacidad máxima no es muy distinta, resultando en 200 personas aproximadamente con vista hacia el centro del patio $^{13}$. Las fachadas de las Casas A, $\mathrm{B}$ y $\mathrm{C}$ son abiertas y las escaleras amplias, lo cual indica que el patio fue diseñado para incluir a un número alto de espectadores en las estructuras periféricas, entre los numerosos pilares de las casas, así como en sus escaleras. Los espectáculos principales se realizaron en el patio mismo, parecido a un teatro o una arena.

Finalmente, hay que mencionar el papel de la escultura en este escenario. Como se mencionó anteriormente, las representaciones de personajes como el gobernante y cautivos marcaron los distintos niveles de acción y tal vez «participaron» en los espectáculos como «observadores» y objetos rituales. Los mascarones en el interior de la Casa $\mathrm{C}$, los cuales son visibles desde el patio, marcaron el interior de la misma como espacio mítico; y otras esculturas, como los frisos de los techos que se encuentran en un estado muy deteriorado, posiblemente servían para fines similares. No obstante, la escritura jeroglífica tuvo un papel distinto y parece haber tenido un lugar muy periférico en las actividades rituales.

Una serie de inscripciones cortas nombra a los retratos de cautivos y los ubica dentro de una narrativa más amplia del pasado reciente. Sin embargo, tanto la Escalinata Jeroglífica como la inscripción dedicatoria de la cornisa de la Casa C son totalmente disfuncionales como textos y no parecen haber transmitido mensajes en situaciones sociales o rituales. La Escalinata Jeroglífica se distingue por su grabado tanto en las huellas como en las contrahuellas (Figura 7), lo que da como resultado una lectura sumamente complicada. Para apreciar los signos, un lector hipotético tiene que cambiar su posición después de cada dos bloques glíficos, bajando y subiendo las escaleras constantemente. Esto significa que la lectura era un proceso comparablemente largo y agotador, y es poco probable que el texto haya sido elaborado con esta intención. Algo parecido se observa en el caso de la inscripción dedicatoria de la cornisa, la cual no sólo está dividida en los dos extremos de la Casa $\mathrm{C}$, sino que además sólo era legible cuando el lector se colocaba inmediatamente debajo de ella, dirigiendo la mirada hacia arriba. Estos patrones indican que ninguno de estos textos puede entenderse como texto público o «discurso de legitimación». Al contrario, se trata de textos íntimamente relacionados con la construcción arquitectónica, otorgándole un carácter muy específico de alto prestigio. Este mecanismo también se refleja, por ejemplo, en los dinteles tallados en otros sitios y requiere de una investigación más detallada en el futuro.

\footnotetext{
${ }^{12}$ Considerando la variable mínima de $\mathrm{m}^{2}$ por persona indicada por Takeshi Inomata (2006: 811-818, tabla 1). Esta variable varía según las normas culturales que estructuran el espacio personal y comunal.

${ }^{13}$ Con un ancho promedio de persona de $80 \mathrm{~cm}$ y asumiendo que se llenaban los escalones de las escaleras y las entradas a las casas.
} 


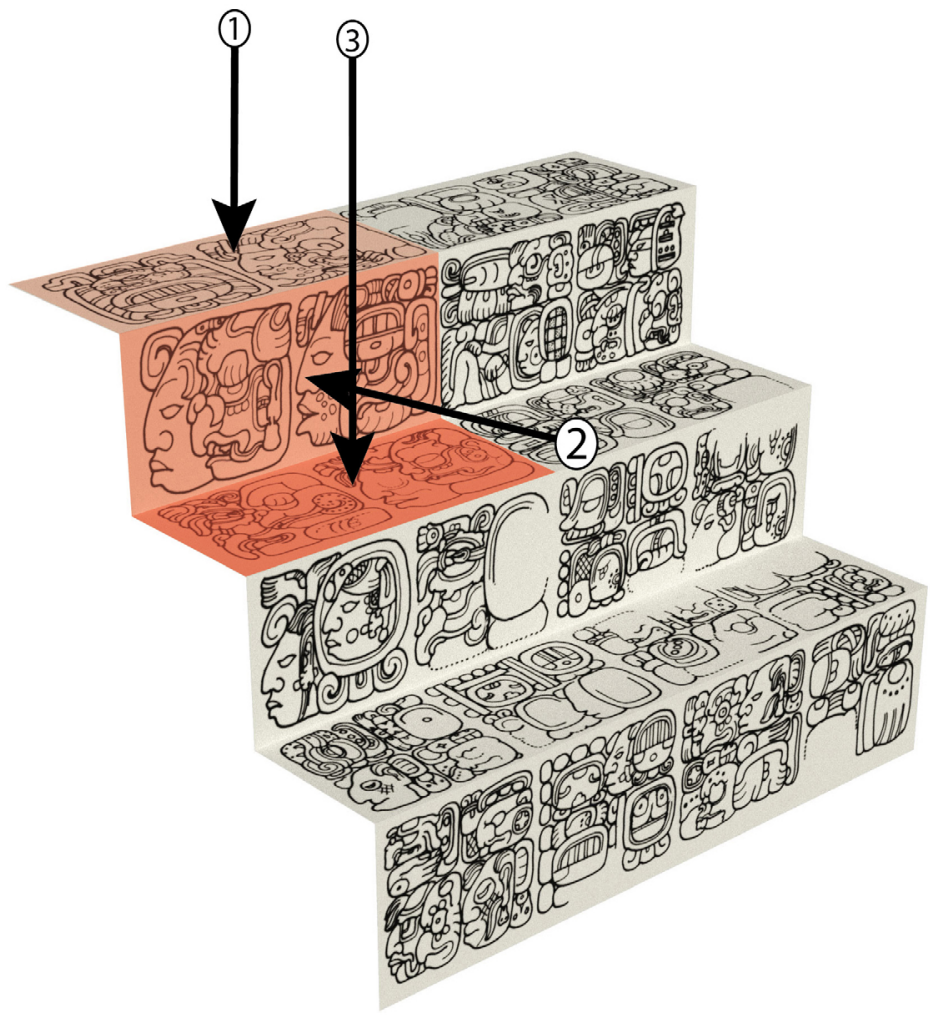

Figura 7. Texto de la Escalinata Jeroglífica de la Casa C. Esquema tridimensional con orden de lectura (basado en dibujo de Linda Schele en Schele y Schele 2000: no. 138).

\section{La Casa $\mathbf{E}$}

Después del análisis del Patio Este, contrapongamos este ejemplo con la Casa E, que fue el primero de los nuevos edificios del Palacio de Janaab Pakal (Robertson 1985a: 7; Stuart 1998: 392, tabla 1; Stuart y Stuart 2008: 156) y es el corazón de este complejo. Los textos del Tablero de los 96 Glifos y el texto pintado en la pared encima del Tablero Oval confirman que la Casa E sirvió como lugar de entronización y como escenario para rituales asociados durante más de un siglo (Stuart 1998: 378, 2006 : 100; Martin y Grube 2000: 174).

Desde los primeros análisis sistemáticos del Palacio ha sido claro que la función y el simbolismo de la Casa $E$ tiene que entenderse en conjunto con una serie de pasillos, conocidos como los Subterráneos, que conectan con este edificio a través de una escalera (Robertson 1985a: 32-35; Schele 1986: 176). Los Subterráneos han sido interpretados recurrentemente como la representación del otro mundo, lugar de los muertos y de la oscuridad (Schele 1986: 119). La Casa E (Figura 8), por el contrario, es percibida como lugar celeste, principalmente por la representación múltiple de una entidad que ha sido bautizada «Cocodrilo Venado Estelar» (Stuart 2003: 1). En un estudio reciente, Michael Carrasco (2015: 394-402) subrayó la importancia de la Casa $\mathrm{E}$ como representación de un lugar mitológico donde el dios GI mató a este ser. Además, propone que el edificio en este contexto servía como umbral simbólico para la entronización de los gobernantes palencanos (véase también García Barrios 2015). Ante esta interpretación, dos de las esculturas integradas en la Casa E son de interés especial: el Trono 1 de los Subterráneos y el Tablero Oval. 


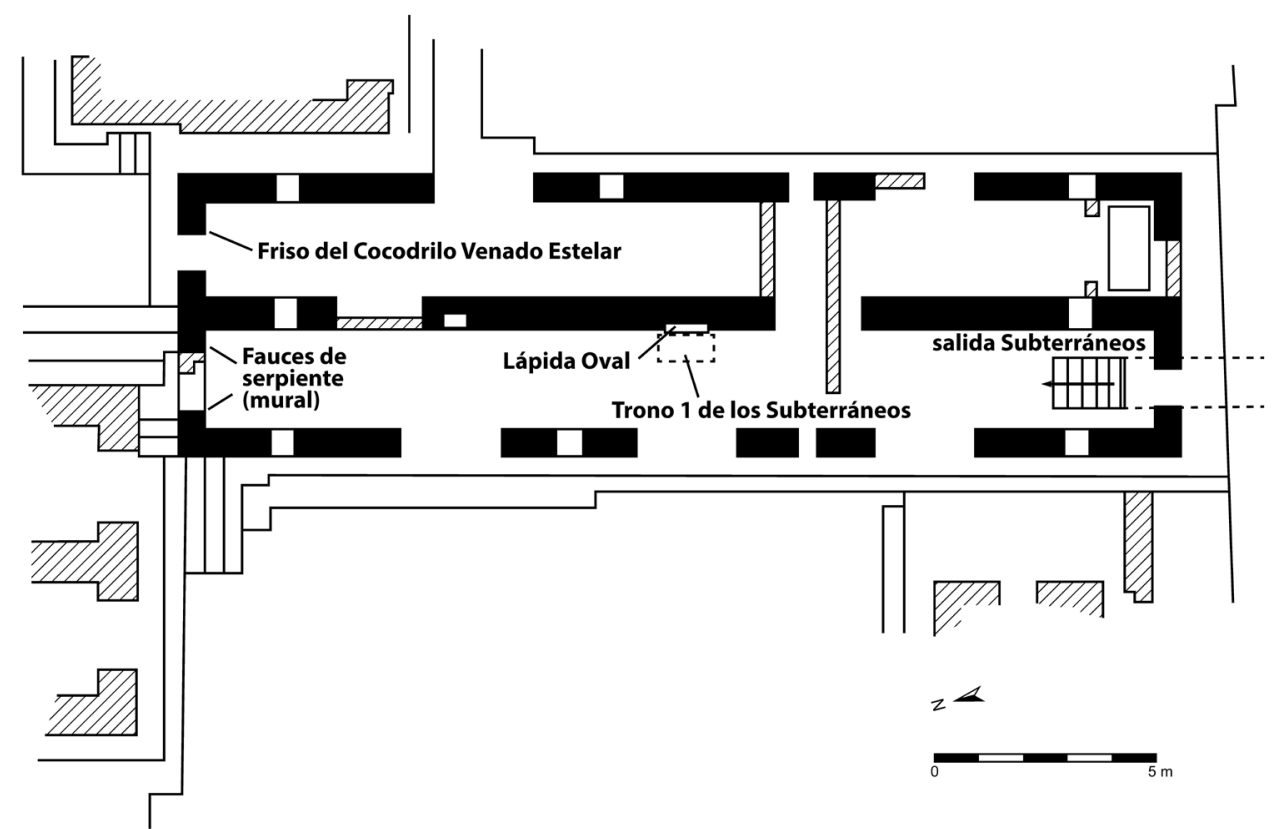

Figura 8. Plano de la Casa E. Los muros rayados son modificaciones posteriores (dibujo basado en el plano de Andrews 1978: 94).

Como han propuesto Guillermo Bernal y otros, el Trono 1 (Figura 9) probablemente servía como banqueta principal de la Casa E en el siglo VII y parece haberse ubicado frente al Tablero Oval (Bernal 2011: 47-49; Peter Mathews 2004, comunicación personal con Parmington 2011: 77) ${ }^{14}$. El grabado hace doble referencia al Cocodrilo Venado Estelar: por un lado, la inscripción menciona un lugar que se relaciona con este ser, y por el otro, el texto mismo forma visualmente el cuerpo del Cocodrilo (Stuart 2003: 2), ya que está enmarcado por su cabeza y sus genitales que tradicionalmente se representan como plato de ofrenda (Stuart 2005: 167; Taube 2009: 105). El texto parece empezar con la expresión dedicatoria [u]tz'i[h]ba[al] '[es] la pintura de', seguido por el nombre descriptivo Ajen Sak Ik' Numil Tachan Numil Takab [...]nal, tentativamente traducido como 'el lugar del «Cocodrilo Venado Estelar», el amanecer(?), el aliento puro, pasando por el cielo, pasando por la tierra'. Si la lectura como 'su pintura' es correcta ${ }^{15}$, es obvio que la ubicación nombrada no puede ser el trono mismo, sino que más bien se tiene que tratar del interior de la Casa E que contaba con muchas pinturas murales (Robertson 1985a: 22), además de por lo menos dos representaciones más del Cocodrilo Venado Estelar en estuco (Robertson 1985a: fig. 81, 83, 85; Schele y Schele 2000: no. 130). El texto confirma esta sospecha, ya que relata que el lugar mencionado es 'la casa de [...] Janaab Pakal'.

\footnotetext{
${ }^{14}$ Otros autores han propuesto que el Trono 2 de los Subterráneos fue la banqueta original que se ubicaba en frente del Tablero Oval (Stuart 2008; Wagner 2017: 4). No obstante, su estado erosionado sugiere que fue expuesta a los elementos durante mucho tiempo y que, por ello, se ubicaba al aire libre.

${ }^{15}$ La raíz $t z$ 'ihb 'pintar, escribir' claramente hace referencia al uso de pigmentos, mientras que la elaboración de escultura en piedra fue expresada con otro término, probablemente $u x u l$. No obstante, el trono no es el único ejemplo donde una inscripción esculpida hace referencia a algo pintado (véase, p. ej., el Bloque 8 de Tzum en von Euw 1977: 66).
} 


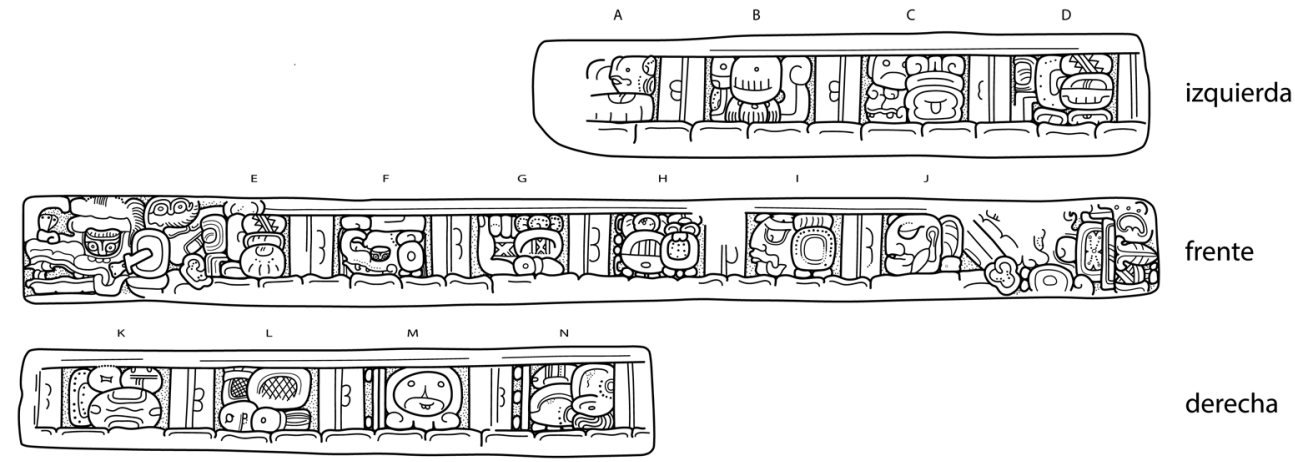

Figura 9. Inscripción en el Trono 1 de los Subterráneos del Palacio de Palenque (dibujo del autor basado en el original y el dibujo de Ian Graham en Stuart 2003: 1, fig. 1).

Al ser una entidad tanto del cielo como de la tierra, está claro que el Cocodrilo Venado es un ser liminar que conecta los dos mundos. La asociación textual con el amanecer refleja su asociación con este fenómeno natural, y es posible que el epíteto tz'ihbal paat 'espalda pintada' ${ }^{16}$ que se encuentra en el Templo XIX (Stuart 2005: 70) tenga que ver con ello, tratándose de una metáfora para los primeros tonos rojos que anuncian la salida del sol. ¿Será que el Cocodrilo Venado simboliza al horizonte mismo, entre cielo y tierra, que divide la noche del día? Independientemente de esta hipótesis ${ }^{17}$, el carácter transicional de este ser es claro y en el caso de la Casa E esta propiedad llegó a caracterizar todo el interior del edificio como espacio de transición, o como umbral entre distintos entornos cósmicos.

Por fuera, la Casa E fue pintada con un total de 132 motivos sobre un fondo blanco (véase el análisis detallado de Robertson 1985a: 12-22). La mayoría de los motivos son elementos florales, pero existen ejemplos aislados de pájaros (Robertson 1985a: 17, fig. 50a-f) y dos cabezas de perfil que emergen de una flor, una de un venado y la otra de un colibrí (Robertson 1985a: 17-18, fig. 49c, g). Varios de los motivos florales combinan los pétalos con una silueta cuadripartita, estableciendo una asociación entre la flor y la cueva. Todos estos motivos hacen referencia a lo que Karl Taube (2004) ha denominado la «montaña florida», un lugar «paradisíaco» de los dioses, los antepasados y entidades celestes que también tiene fuertes conexiones con la respiración vital y ambiental $i k$ ' (lit. 'aliento') y el dios del viento. La Casa $\mathrm{E}$ cuenta con una cantidad extraordinaria de aperturas tipo ventana en forma de $\mathrm{T}$, imitando justamente el signo IK' (Robertson 1985a: 10-12), lo que refuerza la interpretación de la Casa $\mathrm{E}$ como montaña florida. De esta manera, la salida del interior liminar de la Casa E significaba una llegada a esta ubicación celeste. El exterior y el interior fueron espacios conceptualmente muy distintos (pero conectados), lo cual

\footnotetext{
${ }^{16}$ Otra referencia a una 'espalda pintada' aparece en los textos paralelos de las estelas 2 de Aguateca y 16 de Dos Pilas (Matthews 1994; Prager 2013: 254; Valencia 2015: 185-187), donde la pintura o decoración fue borrada de la espalda de (una efigie de) K'awiil. Otros dioses como Chaahk también fueron caracterizados como 'pintados' en algunos textos (García Barrios 2008: 207-212). En el caso del Cocodrilo Venado, parece que la espalda pintada es un atributo diagnóstico general de este ser mitológico (y no de una representación específica), al igual que la 'espalda de cavidades' que también se menciona en el texto del Templo XIX (Stuart 2005: 69-75).

${ }_{17}$ Para un resumen reciente de las diferentes interpretaciones sobre la naturaleza del Cocodrilo Venado Estelar ver Martin (2015: 192-194).
} 
Figura 10. Lápida Oval de la Casa E en Palenque (dibujo de Linda Schele en Schele y

Schele 2000: no. 143).

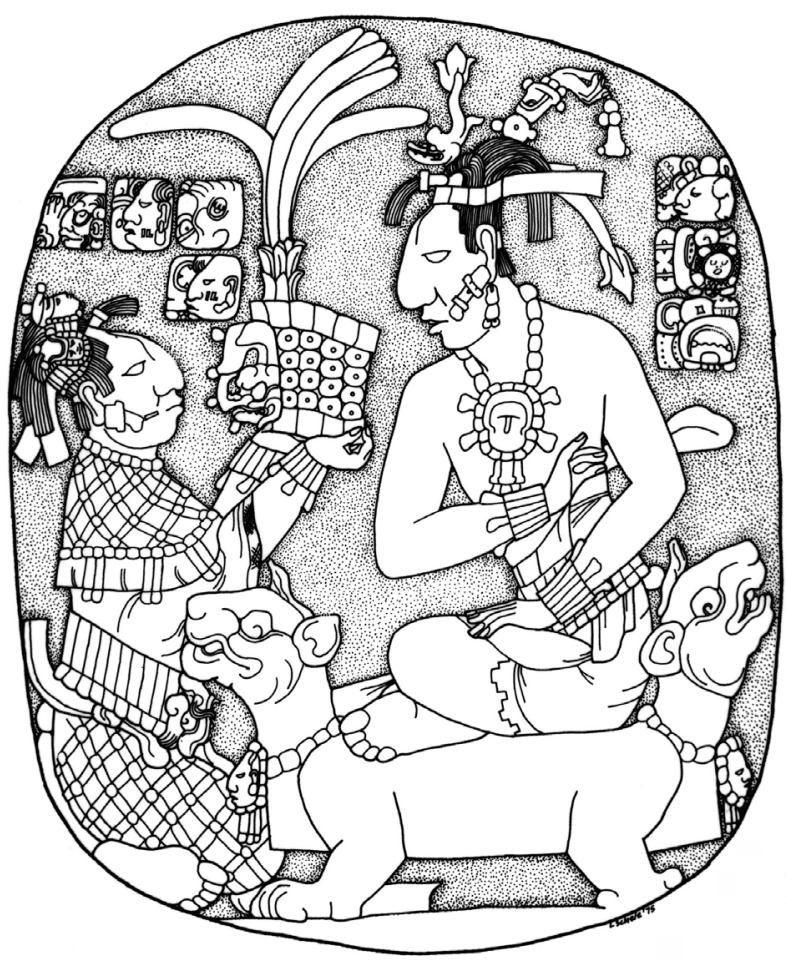

también se refleja en la denominación de los espacios: mientras que el interior era el 'Lugar del «Cocodrilo Venado Estelar»', el exterior era conocido como sak nuk naah 'Gran Casa Blanca' (Stuart 1998: 378; Bernal 2011: 46, n. 61).

Desde el interior de la casa fue posible bajar a los Subterráneos, la versión palencana del otro mundo, pasando por una entrada sobre la cual flota, otra vez, el Cocodrilo Venado, en esta ocasión con el sol en el centro de su cuerpo, el cual se acaba de meter o está por salir (Schele y Schele 2000: no. 130). Es posible entender esta relación entre la Casa E y los Subterráneos a través de una práctica específica que se asocia con estos espacios. Varios autores, como Ana García Barrios (2015) o Michael Carrasco (2015), han discutido de manera contundente que el Cocodrilo Venado jugaba un papel clave en las ceremonias de toma de poder de los gobernantes. No obstante, es curioso que la referencia directa a la entronización de Janaab, la escena del Tablero Oval (véase, p. ej., Schele y Miller 1986: 114; Martin y Grube 2000: 161; Bernal 2011: 46-47) parece enfatizar un nexo mitológico muy distinto (Figura 10).

En la imagen, Janaab Pakal recibe el tocado tubular de su madre, la cual viste el traje de red, vinculado de manera íntima con el mito del dios del maíz y otras deidades como la diosa de la luna y la serpiente acuática Yax Chit Juun Witz' Naah Kan (ver Quenon y Le Fort 1997; Reese-Taylor et al. 2009; García Barrios y Vázquez López 2011). Empero, los textos que acompañan a los personajes no sólo mencionan sus nombres propios, sino también dos teónimos que denominan a las deidades que personifica cada uno. Janaab Pakal está identificado como Juun Yop Ixiim, el joven dios del maíz (Wagner 2017), mientras que su madre, Ix Sak K'uk', personifica un 
aspecto de $\mathrm{GI}^{18}$. Janaab Pakal aquí representa al maíz recién brotado, «de una hoja», lo que en el mito reconstruido corresponde a un episodio poco después de su renacimiento y salida del otro mundo (Wagner 2017: 9-13). Esto indica que Janaab Pakal recreaba el mito de esta deidad en la Casa E. La muerte del dios del maíz y su viaje al otro mundo fue el primer episodio, bajando a los Subterráneos (donde una de las bóvedas estucadas justamente refleja la entrada del dios del maíz en las aguas primordiales; Schele y Schele 2000: no. 130 y 137), sólo para renacer en el «entre-mundos» de la Casa E y salir a la montaña florida (compárese Baudez 1996). La narrativa subyacente tiene antecedentes claros desde el Preclásico, como demuestran los murales de San Bartolo (Saturno et al. 2005), y parece haberse recreado de distintas formas en muchas partes del área maya. El uso de arquitectura en este tipo de rito también ha sido documentado en Copán, donde el Templo 22 refleja un programa iconográficoespacial muy parecido al de la Casa E (Daniel Salazar Lama 2016, comunicación personal), recreando la montaña florida por fuera y el lugar liminar del Cocodrilo Venado Estelar en el interior, así como el otro mundo en un cuarto posterior, que era el más oscuro de todos. Además, el ejemplo de Copán refuerza la relación estrecha con el dios del maíz, ya que abarca muchas esculturas de esta deidad que emerge de la montaña florida (Freidel et al. 1993: 146-155; Pope 2006: 221-228; von Schwerin 2011: 281-294) $)^{19}$.

La personificación del dios del maíz y la recreación del mito de su muerte y resurrección parecen haber sido un paso importante en los rituales de la toma de poder. La narrativa es una figura poderosa de la inmortalidad (Helmke y Kupprat 2016: 44-50) y al identificarse como su protagonista, el nuevo gobernante superaba la muerte de su antecesor-comúnmente su padre- y aparecía como su reencarnación en el cargo del máximo poder. De esta manera, el gobernante no sólo se acercaba a los dioses, sino también reforzó la legitimidad del principio de la herencia patrilineal del trono. Ante la gran importancia de este mito y el rito que lo imponía al ámbito sociopolítico, no sorprende la cantidad de recursos que fueron invertidos en la construcción de un escenario apropiado como es la Casa E.

\section{Conclusiones}

Los dos ejemplos de Palenque confirman lo que en años recientes se ha vuelto un nuevo paradigma en los estudios del arte maya: para «entender» un objeto, en el sentido de determinar su significado, hay que establecer cuáles fueron las prácticas sociales en las que fue involucrado (véase, p. ej., Pope 2006; Werness-Rude y Spencer 2015). Este acercamiento no se restringe a la arquitectura y a los medios integrados en ella (Pearson y Richards 1994), sino a cualquier artefacto que podría tener un significado cultural o personal. De esta manera, el estudio semiótico tiene que ir mucho

\footnotetext{
${ }^{18}$ La transliteración de este teónimo es NAH-\{SAK?\}YUK?-GI. Es el mismo nombre que se encuentra en la Estela I de Copán (B8) como SAK?-YUK?-GI-mi, así como en una serie de textos tempranos del Petén (Hellmuth 1987: 79-101, figs. 136-153; véase también Stuart 2005: 121-122, fig. 190). En Palenque, el nombre de esta deidad cambió en la segunda mitad del siglo VII, cuando empieza a aparecer la triada de dioses patronos locales.

19 Aún habrá que aclarar cómo se inserta el mito de la decapitación del cocodrilo por parte de GI (Stuart 2005: 68-77; ver Carrasco 2015: 394-402) o Chaahk (Ana García Barrios, comunicación personal 2016), así como el diluvio primordial (Velásquez 2006; García Barrios 2015), en la narrativa de la muerte del dios del maíz. La aparente existencia de diferentes versiones contemporáneas del mito dificulta el análisis.
} 
más allá del ejercicio iconográfico. En muchos casos, la identificación de signos y su interacción con otros no es posible sin saber en qué situaciones tanto ellos como sus soportes fueron creados, utilizados y percibidos.

En el campo de los estudios mayas, este acercamiento presenta, por supuesto, muchos obstáculos. Para empezar, no podemos observar la interacción social de manera inmediata, sino sólo a través del registro arqueológico, con todas sus limitaciones. En los casos presentados fue necesario extraer información contextual de diferentes tipos de materiales, como el arreglo espacial, la estratigrafía, los textos, las imágenes $\mathrm{y}$, finalmente, una cantidad considerable de datos secundarios que provienen de otras regiones y temporalidades del área maya. De esta manera, se estudiaron varios motivos visuales con base en la reconstrucción de rituales específicos que involucraban la personificación de númenes por parte del gobernante y la recreación teatral de narrativas mitológicas.

Las Casas $\mathrm{C}$ y E recibieron un significado muy concreto en estas ocasiones: literalmente servían como escenarios cosmológicos cuando Janaab Pakal aparecía como Balun Yookte' K'uh o como el dios del maíz. ¿Pero qué otras funciones tenían estos edificios? ¿Cómo se percibían cuando no hubo espectáculos o cuando Janaab Pakal no estaba presente? La arquitectura mitológica no deja de funcionar cuando no recibe un uso activo, sino sigue activando los recuerdos de los eventos que se han desarrollado en ella, así que transmite las mismas narrativas de manera constante. Este mecanismo no es meramente religioso, sino que tiene un fuerte componente social e incluso político. Probablemente hubo recreaciones de lugares primordiales en muchos estratos sociales, pero las casas de Janaab Pakal eran lugares mitológicos permanentes. En este sentido, parece que el gobernante se distinguía por tener una conexión constante, explícita y bastante pública con los dioses y los héroes culturales.

Agradecimientos: Agradezco a la Universidad Nacional Autónoma de México, la Coordinación de Humanidades y el Instituto de Investigaciones Antropológicas donde actualmente estoy realizando una estancia posdoctoral. Muchas gracias a Daniel Salazar Lama y Ana García Barrios por la invitación de participar en el simposio Iconografía Maya: problemáticas y nuevas perspectivas de análisis en el marco del X Congreso Internacional de Mayistas, donde se presentó una primera versión de este trabajo. Además, expreso mi agradecimiento sincero a Edwin Barnhart por su permiso de reproducir una sección de su mapa de Palenque, a Justin Kerr por el permiso de reproducir un detalle de su fotografía de K5628, así como a Daniel Salazar Lama, Pilar Regueiro Suárez y los revisores anónimos por sus comentarios, sugerencias y crítica.

\section{Referencias}

Andrews, George F. 1978. Architectural Survey: Palenque, Chiapas, Mexico. The Palace. Eugene: University of Oregon. Documento inédito.

Ara, Domingo de. 1986 (1616). Vocabulario de lengua tzeldal según el orden de Copanabastla, Mario Humberto Ruz, ed. Fuentes para el Estudio de la Cultura Maya 4. México: Centro de Estudios Mayas, Instituto de Investigaciones Filológicas, Universidad Nacional Autónoma de México.

Barnhart, Edwin Lawrence. 2001. The Palenque Mapping Project: Settlement and Urbanism at an Ancient Maya City. Tesis Doctoral. Graduate School. University of Texas at Austin. 
Baudez, Claude F. 1996. «Arquitectura y escenografía en Palenque: Un ritual de entronización». RES: Anthropology and Aesthetics 29/30: 172-179.

Baudez, Claude F. y Peter Mathews. 1979. «Capture and Sacrifice at Palenque», en Tercera Mesa Redonda de Palenque, Merle Greene Robertson y Donnan Call Jeffers, eds., pp. 31-40. Monterey: Pre-Columbian Art Research Center.

Bernal Romero, Guillermo. 2011. El señorío de Palenque durante la era de K'inich Janaahb' Pakal y K'inich Kan B'ahlam (615-702 d.C.). Tesis Doctoral. Posgrado en Estudios Mesoamericanos. Universidad Nacional Autónoma de México.

Boot, Erik. 2009. «The Updated Preliminary Classic Maya - English, English- Classic Maya Vocabulary of Hieroglyphic Readings». Mesoweb. http://www.mesoweb.com/resources/ vocabulary/Vocabulary-2009.01.pdf.

Carrasco, Michael D. 2005. The Mask Flange Iconographic Complex: The Art, Ritual, and History of the Maya Sacred Image. Tesis Doctoral. Graduate School. University of Texas at Austin.

. 2015. «Epilogue: Portals, Turtles, and Mythic Places», en Maya Imagery, Architecture, and Activity: Space and Spatial Analysis in Art History, Maline D. Werness-Rude y Kaylee R. Spencer, eds., pp. 374-411. Albuquerque: University of New Mexico Press.

Carrasco, Michael D. y Kerry Hull. 2002. «The Cosmogonic Symbolism of the Corbeled Vault in Maya Architecture». Mexicon 24 (2): 26-32.

Child, Mark B. 2007. «Ritual Purification and the Ancient Maya Sweatbath at Palenque», en Palenque: Recent Investigations at the Classic Maya Center, Damien B. Marken, ed., pp. 233-262. Lanham: Altamira Press.

Colas, Pierre R. 2004. Sinn und Bedeutung klassischer Maya-Personennamen. Typologische Analyse von Anthroponymphrasen in den Hieroglypheninschriften der klassischen Maya-Kultur als Beitrag zur allgemeinen Onomastik. Acta Mesoamericana 15. Markt Schwaben: Anton Saurwein.

Eberl, Markus y Christian M. Prager. 2005. «B'olon Yokte' K'uh: Maya Conceptions of War, Conflict, and the Underworld», en Wars and Conflicts in Prehispanic Mesoamerica and the Andes, Peter Eeckhout y Geneviève Le Fort, eds., pp. 28-36. BAR International Series 1385. Oxford: Archaeopress.

Eliade, Mircea. 2001 (1949). El mito del eterno retorno: arquetipos y repetición. Buenos Aires: Emecé.

Freidel, David A., Linda Schele y Joy Parker. 1993. Maya Cosmos: Three Thousand Years on the Shaman's Path. Nueva York: William Morrow.

Euw, Eric von. 1977. Corpus of Maya Hieroglyphic Inscriptions, Vol. 4, Part 1. Cambridge: Peabody Museum of Archaeology and Ethnology, Harvard University.

García Barrios, Ana. 2008. Chaahk, el dios de la lluvia, en el periodo Clásico maya: aspectos religiosos y políticos. Tesis Doctoral. Facultad de Geografía e Historia. Universidad Complutense de Madrid.

- 2015. «El mito del diluvio en las ceremonias de entronización de los gobernantes mayas. Agentes responsables de la decapitación del saurio y nuevas fundaciones». Estudios de Cultura Maya 45: 9-48. https://doi.org/10.1016/S0185-2574(15)30001-0.

García Barrios, Ana y Verónica Amellali Vázquez López. 2011. «The Weaving of Power: Women's Clothing and Protocol in the Seventh-Century Kingdom of Kaanu'l». Latin American Indian Literatures Journal 27 (1): 59-95.

Garza, Mercedes de la, Guillermo Bernal Romero y Martha Cuevas García. 2012. PalenqueLakamha': una presencia inmortal del pasado indígena. México: Fondo de Cultura Económica, El Colegio de México, Fideicomiso Historia de las Américas. 
Grofe, Michael J. 2009. «The Name of God L: B'olon Yokte'K'uh?». Wayeb Notes 30. https:// www.wayeb.org/notes/wayeb_notes0030.pdf.

Grube, Nikolai. 1996. «Palenque in the Maya World», en Eighth Palenque Round Table, 1993, Martha J. Macri y Jan McHargue, eds., pp. 1-14. San Francisco: Pre-Columbian Art Research Institute.

Grube, Nikolai, Simon Martin y Marc Zender. 2002. Notebook for the XXVIth Maya Hieroglyphic Forum at Texas. Part II: Palenque and Its Neighbors. Austin: Institute of Latin American Studies, The University of Texas at Austin.

Hellmuth, Nicholas M. 1987. Monster und Menschen in der Maya-Kunst. Eine Ikonographie der alten Religionen Mexikos und Guatemalas. Graz: Akademische Druck- u. Verlagsanstalt.

Helmke, Christophe y Felix Kupprat. 2016. «Where Snakes Abound: Supernatural Places of Origin and Founding Myths in the Titles of Classic Maya Kings», en Places of Power and Memory in Mesoamerica's Past and Present: How Sites, Toponyms and Landscapes Shape History and Remembrance, Daniel Graña-Behrens, ed., pp. 33-83. Estudios Indiana 9. Berlín: Ibero-Amerikanisches Institut, Gebr. Mann Verlag.

Inomata, Takeshi. 2006. «Plazas, Performers, and Spectators: Political Theaters of the Classic Maya». Current Anthropology 47 (5): 805-842. https://doi.org/10.1086/506279.

Kerr, Justin. 2008. «Maya Vase Database: An Archive of Rollout Photographs». Foundation for the Advancement of Mesoamerican Studies, Inc. (FAMSI). http://www.mayavase.com.

Kettunen, Harri y Christophe Helmke. 2010. La escritura jeroglifica maya. Acta Ibero-Americana Fennica. Madrid: Instituto Iberoamericano de Finlandia.

Kinney, Dale. 2011. «Introduction», en Reuse Value: Spolia and Appropriation in Art and Architecture from Constantine to Sherrie Levine, Richard Brilliant y Dale Kinney, eds., pp. 1-11. Farnham: Ashgate.

Koontz, Rex, Kathryn Reese-Taylor y Annabeth Headrick, eds. 2001. Landscape and Power in Ancient Mesoamerica. Boulder y Oxford: Westview Press.

López Austin, Alfredo y Leonardo López Luján. 2009. Monte Sagrado-Templo Mayor. El cerro y la pirámide en la tradición religiosa mesoamericana. México: Instituto Nacional de Antropología e Historia, Instituto de Investigaciones Antropológicas, Universidad Nacional Autónoma de México.

Macri, Martha J. y Matthew G. Looper. 2003. The New Catalog of Maya Hieroglyphs Volume 1: The Classic Period Inscriptions. Norman: University of Oklahoma Press.

Martin, Simon. 2015. «The Old Man of the Maya Universe: A Unitary Dimension to Ancient Maya Religion», en Maya Archaeology 3, Charles Golden, Stephen Houston y Joel Skidmore, eds., pp. 186-227. San Francisco: Precolumbia Mesoweb Press.

Martin, Simon y Nikolai Grube. 2000. Chronicle of the Maya Kings and Queens: Deciphering the Dynasties of the Ancient Maya. Londres: Thames and Hudson.

-2008. Chronicle of the Maya Kings and Queens: Deciphering the Dynasties of the Ancient Maya. $2^{\text {a }}$ edición revisada. Londres: Thames and Hudson.

Mathews, Peter y Linda Schele. 1974. «Lords of Palenque: The Glyphic Evidence», en Primera Mesa Redonda de Palenque, Part 1, 1973, Merle Greene Robertson, ed., pp. 63-76. Pebble Beach: Robert Louis Stevenson School, Pre-Columbian Art Research Institute.

Matthews, Paul H. 1994. "Ch'akah U Tz'ibal: The Axing of History at Seibal». Texas Notes on Precolumbian Art, Writing, and Culture 65.

Maudslay, Alfred P. 1889-1902. Biologia Centrali-Americana; or, Contributions to the Knowledge of the Fauna and Flora of Mexico and Central America. Archaeology. 4 tomos. Londres: R.H. Porter, Dulau and Co. 
Morán, Fray Pedro. 1836 (1695). Arte y vocabulario de la lengua Cholti. MS 497.4, folio M79. Guatemala: American Philosophical Society, Academia de Ciencias de Guatemala.

Parmington, Alexander. 2011. Space and Sculpture in the Classic Maya City. Cambridge: Cambridge University Press.

Pearson, Mike Parker y Colin Richards. 1994. «Architecture and Order: Spatial Representation and Archaeology», en Architecture and Order: Approaches to Social Space, Michael Parker Pearson y Colin Richards, eds., pp. 34-66. Londres y Nueva York: Routledge.

Polyukhovych, Yuriy. 2005. «A Possible Phonetic Substitution for T533 or 'Ajaw Face'». Glyph Dwellers 33. http://glyphdwellers.com/pdf/R33.pdf.

Pope, Elizabeth I. 2006. Mythic Architecture and Drama in Ancient Mesoamerica: The Manifestation of the Mythological Landscape in the Historical World. Tesis Doctoral. Graduate School. University of Texas at Austin.

Prager, Christian M. 2006. Is T533 a Logograph for BO:K 'Smell, Odour'? Documento inédito.

. 2013. Übernatürliche Akteure in der Klassischen Maya-Religion: Eine Untersuchung zu intrakultureller Variation und Stabilität am Beispiel des k'uh «Götter»-Konzepts in den religiösen Vorstellungen und Überzeugungen Klassischer Maya-Eliten (250 - 900 n. Chr.). Tesis Doctoral. Philosophische Fakultät. Universität Bonn.

Quenon, Michel y Geneviève Le Fort. 1997. «Rebirth and Resurrection in Maize God Iconography», en Tha Maya Vase Book 5, Justin Kerr y Barbara Kerr, eds., pp. 884-902. Nueva York: Kerr Associates.

Reese, Kathryn. 1996. Narratives of Power: Late Formative Public Architecture and Civic Center Design at Cerros, Belize. Tesis Doctoral. University of Texas at Austin.

Reese-Taylor, Kathryn, Peter Mathews, Julia Guernsey y Marlene Fritzler. 2009. «Warrior Queens among the Classic Maya», en Blood and Beauty: Organized Violence in the Art and Archaeology of Mesoamerica and Central America, Heather Orr y Rex Koontz, eds., pp. 39-72. Los Angeles: Cotsen Institute of Archaeology Press.

Robertson, Donald. 1974. «Some Remarks on Stone Relief Sculpture at Palenque», en Primera Mesa Redonda de Palenque, Part II, Merle Greene Robertson, ed., pp. 103-108. Pebble Beach: Robert Louis Stevenson School.

Robertson, Merle Greene. 1985a. The Sculpture of Palenque. Volume II: The Early Buildings of the Palace and the Wall Paintings. Princeton: Princeton University Press.

. 1985b. The Sculpture of Palenque. Volume III: The Late Buildings of the Palace. Princeton: Princeton University Press, J. Paul Getty Trust.

-1991. The Sculpture of Palenque. Volume IV: The Cross Group, the North Group, the Olvidado, and Other Pieces. Princeton: Princeton University Press.

Ruz Lhuillier, Alberto. 2013 (1973). El Templo de las Inscripciones, Palenque. México: Fondo de Cultura Económica.

Saturno, William A., Karl A. Taube y David Stuart. 2005. The Murals of San Bartolo, El Petén, Guatemala. Part 1: The North Wall. Ancient America 7. Barnardsville: Center for Ancient American Studies.

Schele, Linda. 1986. "Architectural Development and Political History at Palenque», en City-States of the Maya: Art and Architecture, Elizabeth P. Benson, ed., pp. 110-137. Denver: Rocky Mountain Institute for Pre-Columbian Studies.

- 1994. «Some Thoughts on the Inscriptions of House C», en Seventh Palenque Round Table, 1989, Merle Greene Robertson y Virginia M. Fields, eds., pp. 1-10. San Francisco: Pre-Colombian Art Research Institute. 
. 1998. «The Iconography of Maya Architectural Façades during the Late Classic Period», en Function and Meaning in Classic Maya Architecture, Stephen D. Houston, ed., pp. 479-517. Washington, D.C.: Dumbarton Oaks Research Library and Collection. Schele, Linda y David A. Freidel. 1990. A Forest of Kings: The Untold Story of the Ancient Maya. Nueva York: Morrow.

Schele, Linda y Peter Mathews. 1998. The Code of Kings: The Language of Seven Sacred Maya Temples and Tombs. Nueva York: Touchstone.

Schele, Linda y Mary Ellen Miller. 1986. The Blood of Kings: Dynasty and Ritual in Maya Art. Nueva York y Fort Worth: G. Braziller, Kimbell Art Museum.

Schele, Linda y David Schele. 2000. «The Linda Schele Drawings Collection». Foundation for the Advancement of Mesoamerican Studies, Inc. (FAMSI) http://research.famsi.org/ schele.html.

Schwerin, Jennifer von. 2011. «The Sacred Mountain in Social Context. Symbolism and History in Maya Architecture: Temple 22 at Copan, Honduras». Ancient Mesoamerica 22 (2): 271-300.

Spencer, Kaylee R. 2015. «Locating Palenque's Captive Portraits: Space, Identity, and Spectatorship in Classic Maya Art», en Maya Imagery, Architecture, and Activity: Space and Spatial Analysis in Art History, Maline D. Werness-Rude y Kaylee R. Spencer, eds., pp. 229-270. Albuquerque: University of New Mexico Press.

Stephens, John L. 1841. Incidents of Travel in Central America, Chiapas, and Yucatan, Tomo 2. Londres: John Murray.

Stuart, David. 1998. «»The Fire Enters His House»: Architecture and Ritual in Classic Maya Texts», en Function and Meaning in Classic Maya Architecture, Stephen D. Houston, ed., pp. 373-425. Washington, D.C.: Dumbarton Oaks Research Library and Collection.

- 2003. «A Cosmological Throne at Palenque». Mesoweb. http://www.mesoweb.com/ stuart/notes/Throne.pdf.

- 2005. The Inscriptions from Temple XIX at Palenque: A Commentary. San Francisco: Pre-Columbian Art Research Institute.

- 2006. Sourcebook for the $30^{\text {th }}$ Maya Meetings, March 13-19, 2006. Austin: The Mesoamerica Center, Department of Art and Art History, The University of Texas at Austin. . 2008. «The Throne in the Basement». Maya Decipherment: Ideas on Ancient Maya Writing and Iconography. Blog, David Stuart, ed. https://mayadecipherment. com/2008/11/03/the-throne-in-the-basement/.

—. 2014. «Reconstructing a Stucco Text from Palenque's Palace». Maya Decipherment: Ideas on Ancient Maya Writing and Iconography. Blog, David Stuart, ed. https:// decipherment.wordpress.com/2014/07/15/reconstructing-a-stucco-text-from-palenquespalace/.

Stuart, David y George E. Stuart. 2008. Palenque: Eternal City of the Maya. New Aspects of Antiquity. Londres: Thames and Hudson.

Taube, Karl A. 1998. «The Jade Hearth: Centrality, Rulership, and the Classic Maya Temple», en Function and Meaning in Classic Maya Architecture, Stephen D Houston, ed., pp. 427-478. Washington, D.C.: Dumbarton Oaks Research Library and Collection.

. 2004. «Flower Mountain: Concepts of Life, Beauty and Paradise among the Classic Maya». RES: Anthropology and Aesthetics 45: 69-98.

- 2009. «The Womb of the World: The Cuauhxicalli and Other Offering Bowls of Ancient and Contemporary Mesoamerica», en Maya Archaeology 1, Charles Golden, Stephen Houston y Joel Skidmore, eds., pp. 86-106. San Francisco: Precolumbia Mesoweb Press. 
Tokovinine, Alexandre. 2012. «Writing Color: Words and Images of Colors in Classic Maya Inscriptions». RES: Anthropology and Aesthetics 61/62: 283-299.

Tsukamoto, Kenichiro. 2014. Politics in Plazas: Classic Maya Ritual Performance at El Palmar, Campeche, Mexico. Tesis Doctoral. School of Anthropology. University of Arizona.

Valencia Rivera, Rogelio. 2015. El rayo, la abundancia y la realeza: análisis de la naturaleza del dios K'awiil en la cultura y la religión mayas. Tesis Doctoral. Facultad de Geografía e Historia. Universidad Complutense de Madrid.

Velásquez García, Erik. 2006. «The Maya Flood Myth and the Decapitation of the Cosmic Caiman». The PARI Journal 7 (1): 1-10.

- 2009. Los vasos de la entidad política de 'I $k$ ': una aproximación histórico-artística. Estudio sobre las entidades anímicas y el lenguaje gestual y corporal en el arte maya clásico. Tesis Doctoral. Posgrado en Historia del Arte. Universidad Nacional Autónoma de México.

Wagner, Elisabeth. 2017. «Jun Yop Ixiim. Another Appellative for the Ancient Maya Maize God». Textdatenbank und Wörterbuch des Klassischen Maya Research Note 8. https:// doi.org/10.20376/IDIOM-23665556.17.rn008.en.

Wayeb. 2008. Wayeb Drawing Archive. http://www.wayeb.org/resources-links/wayeb-resources/ wayeb-drawing-archive.

Werness-Rude, Maline D. y Kaylee R. Spencer, eds. 2015. Maya Imagery, Architecture, and Activity: Space and Spatial Analysis in Art History. Albuquerque: University of New Mexico Press. 